\title{
Kompatibilnost fungicida i arbuskularnih mikoriznih gljiva u proizvodnji rajčice na otvorenom
}

\section{Sažetak}

Arbuskularne mikorizne gljive (AMG) su korisni mikroorganizmi tla koji žive u obliku simbioze s korijenjem velikog broja biljnih vrsta, uključujući $i$ većinu ekonomski važnih poljoprivrednih kultura, u koje se za područje Hrvatske ubraja i rajčica. Rajčica ima visoki stupanj prirodne sposobnosti vezivanja s AMG, čije su prednosti najvećim dijelom povezane s boljom kondicijom biljaka i otpornosti na različite biotske i abiotske čimbenike. Primjena AMG je ograničena proizvodnim uvjetima, između ostalih primjenom fungicida koja se redovito provodi u proizvodnji rajčice za suzbijanje gljivičnih bolesti. lako se fungicidiu proizvodnji rajčice uglavnom primjenjuju folijarno, značajne količine primijenjene djelatne tvari mogu indirektno dospjeti u gornji sloj tla i negativno utjecati na razvoj AMG. Cilj ovog preglednog rada je, temeljem dostupnih literaturnih podataka i dosadašnjih istraživanja, prikazati kompatibilnost AMG i fungicida dozvoljenih u Hrvatskoj za primjenu u proizvodnji rajčice na otvorenome.

Ključne riječi: arbuskularne mikorizne gljive, mikoriza, Solanum lycopersicum L., fungicidi, kompatibilnost

\section{Uvod}

Literatura navodi mogućnost primjene arbuskularnih mikoriznih gljiva (AMG) u proizvodnji rajčice za unaprjeđenje produktivnosti, održivosti i kvalitete proizvodnje (Cavagnaro i sur., 2006; Conversa i sur., 2007; Baum, 2015; Rouphael i sur., 2015; Bowles i sur., 2016). AMG imaju važnu ulogu u održavanju plodnosti tla i općenito ishrani bilja (Giovannetti i Avio, 2002). Brojni autori ističu prednosti mikorize u proizvodnji rajčice navodeći učinkovitije usvajanje hraniva, povećanju tolerantnosti na uvjete suše i visok salinitet tla (Al-Karaki, 2006; Abdel Latef i Chaoxing, 2011; Ortas i sur., 2013; Watts-Williams i sur., 2014).

Primjena AMG u poljoprivredi uvjetovana je agrotehničkim zahvatima (Zocco i sur., 2008). Ranije spomenute prednosti i djelovanje AMG može biti narušeno primjenom pesticida, posebice fungicida koji se u suvremenoj poljoprivredi redovito koriste $u$ kontroli patogenih gljiva (Sukarno i sur., 1993). Gljivične bolesti su najveći uzrok gubitka usjeva u svijetu (Yadav i Aggarwal, 2014) pa je kontrola bolesti i njihovo suzbijanje fungicidima sastavni dio poljoprivredne proizvodnje.

Na području Hrvatske proizvodnja rajčice čini $17 \%$ od ukupne proizvodnje povrća (Statistički ljetopis, 2017). Uzgoj rajčice za preradu koncentriran je u Istarskoj županiji s proizvodnjom od oko 12 tisuća tona na površini od otprilike 179 ha (Podravka, 2018).

Općenito, gubici od štetočina u povrćarskoj proizvodnji predstavljaju prosječno polovicu ukupnog prinosa (Maceljski i sur., 2004). Prema Šubiću (2016) štete u proizvodnji rajčice mogu u pojedinim nepovoljnim godinama biti i potpune, a na njihovu pojavu najvećim djelom utječu način uzgoja, abiotski čimbenici i mjere primijenjene u suzbijanju bolesti rajčice. Različiti abiotski čimbenici, od kojih prednjače česte oborine i visoka vlaga zraka, dovode do česte

Jana Klanjac, mag.ing.agr., Kristina Grozić, mag.ing.agr., dr.sc. Smiljana Goreta Ban, dr.sc. Dean Ban, dr.sc. Igor Pasković, Institut za poljoprivredu i turizam, K. Huguesa 8, 52440 Poreč, Hrvatska dr.sc. Dario lvić, Zavod za zaštitu bilja, Hrvatski centar za poljoprivredu, hranu i selo, Svetošimunska cesta 25, 10000 Zagreb, Hrvatska dr.sc. Tomislav Radić, Institut za jadranske kulture i melioraciju krša, Put Duilova 11, 21000 Split, Hrvatska Autor za korespondenciju:kristina.grozi@@gmail.com 
primjene fungicida koje su u pojedinim godinama nedovoljne za potpuno suzbijanje bolesti rajčice (Borošić, 2016).

Stoga možemo zaključiti da intenzivna poljoprivredna proizvodnja dovodi do potrebe pronalaska održivih praksi koje će smanjiti negativan utjecaj na okoliš i optimalno koristiti resurse (Zrnić i Širić, 2017).

\section{Mikoriza}

Mikoriza je najrasprostranjeniji odnos između mikroorganizama i viših biljaka, a podrazumijeva simbiozu gljiva i korijena većine kopnenih biljnih vrsta (Marschner, 2012). Prisutna je kod $83 \%$ dvosupnica i jednosupnica dok su sve golosjemenjače prirodno mikorizirane. Mikoriza nije prisutna kod određenih porodica biljaka poput Cruciferae i Chenopodiaceae, a rijetka je ili izostaje kod Proteaceae. Također, može izostati u suviše suhim ili vlažnim tlima, onečišćenim tlima i tlima visokog saliniteta te u tlima čija je plodnost izrazito niska ili visoka (Smith i Read, 2008).

Različitost u morfologiji i fiziologiji razvrstava mikorize u dvije glavne grupe: endomikoriza i ektomikoriza (Slika 1). lako se obje vrste mikoriza mogu primijeniti u poljoprivrednoj proizvodnji, najčešće je zastupljena endomikoriza, odnosno AMG.

a) Endomikoriza

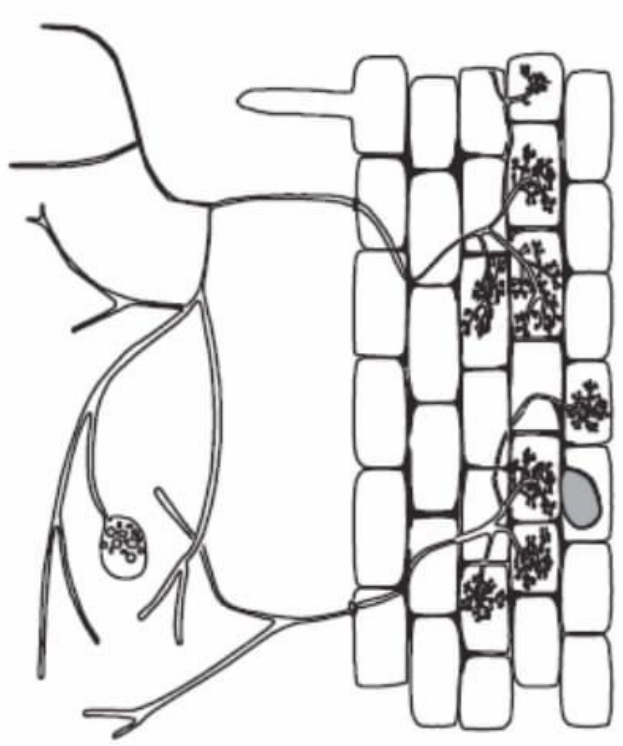

b) Ektomikoriza

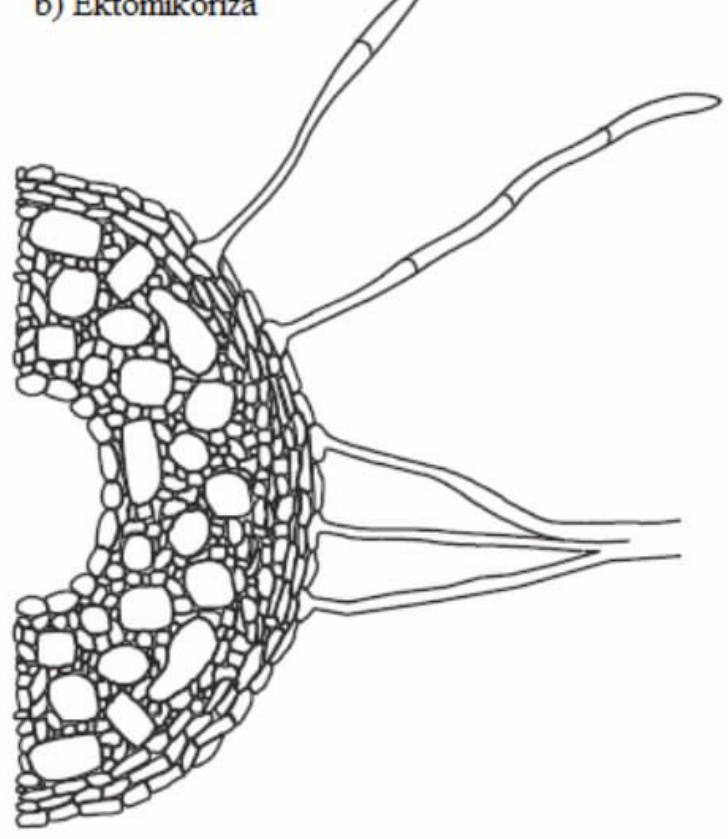

Slika 1. Morfologija a) AMG i b) ektomikoriza (Marschner, 2012)

Figure 1 The main structural features of a) AMF and b) ectomycorrhiza (Marschner, 2012)

Endomikoriza podrazumijeva tvorbu staničnih struktura gljive unutar stanica korijena i međustanični rast. Stanične membrane gljiva i biljaka u direktnom su kontaktu pa je olakšan prijenos hraniva (Marschner, 2012). Interakcija gljive i biljke kod ektomikorize osigurana je na nekoliko načina, ali stanične strukture gljive ne prodiru u stanice korijena. Izmjena tvari događa se na način da gljiva stvara omotač hifa uokolo korijena ili hife prodiru u međustanični prostor korteksa i formiraju Hartigovu mrežu koja okružuje stanice korteksa, čime povećava površinu interakcije gljive i korijena biljke domaćina (Marschner, 2012). 
Postoji nekoliko vrsta endomikoriza, no najučestalija je arbuskularna mikoriza (AM) (Smith i Read, 2008), koja je od ranije poznata pod nazivom vezikularno-arbuskularna mikoriza (VAM). AMG pripadaju zasebnom odjeljku Glomeromycota, a taksonomski su svrstane u pet redova (Archaeosporales, Gigasporales, Glomerales, Diversisporales i Paraglomerales) te unutar njih 14 porodica, 29 rodova i oko 230 vrsta (Oehl i sur., 2011). Interakcija gljive i korijena osigurana je stvaranjem arbuskula koje predstavljaju glavno mjesto razmjene tvari s biljkom domaćinom. Također, AMG stvaraju i međustanične hife i micelij koji se prostire u tlo. Osim arbuskula, AMG mogu tvoriti i vezikule koje predstavljaju rezervoar lipida (Marschner, 2012).

\section{Mikoriza u poljoprivrednoj proizvodnji}

U poljoprivrednoj proizvodnji najčešće se primjenjuju AMG koje imaju ulogu biostimulatora i osiguravaju niz prednosti za biljku domaćina. Biljka domaćin opskrbljuje gljive ugljikovim spojevima koje same ne mogu sintetizirati, a biljke imaju korist u vidu efikasnije apsorpcije hraniva i vode (Giovannetti i Avio, 2002). Osim efikasnijeg usvajanja hraniva, AMG povećavaju otpornost biljke na abiotske stresove, prvenstveno sušu i visok salinitet tla (Auge, 2004; Porcel i sur., 2012) te otpornost na bolesti (Pozo i Azcón-Aguilar, 2007). Također, AMG ublažavaju negativan učinak biljkom usvojenih teških metala ili teških metala prisutnih u okolnom tlu (Berruti i sur., 2015), čime imaju i direktan pozitivan utjecaj na ekosustav. Poboljšavaju strukturu i agregaciju tla, povećavaju sadržaj organske tvari (Schalamuk i sur., 2014) te utječu na biološku aktivnost tla.

lako su AMG prirodno prisutne u tlu, zbog bolje iskoristivosti, biljke se mogu inokulirati s komercijalno dostupnim AMG (Baum i sur., 2015). Danas se u povrćarskoj proizvodnji koriste različiti komercijalni pripravci s učinkovitim izolatima AMG. Inokulacija se odvija kod proizvodnje presadnica kako bi korijen presadnica bio koloniziran prije presađivanja na otvoreno (Douds i sur., 2012). Kod proizvodnje rajčice najčešće se primjenjuju vrste roda Glomus (Poulton i sur., 2002; Copeta i sur., 2011; Conversa i sur., 2013; Ortas i sur., 2013; Baum i sur., 2015).

\section{Fungicidi u proizvodnji rajčice na otvorenom}

Fungicidi se u proizvodnji rajčice primjenjuju folijarno ili putem tla, za preventivno ili kurativno suzbijanje gljivičnih i pseudogljivičnih bolesti, od kojih su u Hrvatskoj značajne: plamenjača rajčice [Phytophthora infestans (Mont.) de Bary] (Cvjetković, 2016), koncentrična pjegavost [Alternari solani (Ellis \& G. Martin) L.R. Jones \& Grout], septorijska pjegavost (Septoria lycopersici Speg.) (Šubić, 2016), pepelnica rajčice [Leveillula taurica (Lév.) G. Arnaud, Pseudoidium neolycopersici (L. Kiss) L. Kiss] (Miličević, 2016a); a ponekad se pojave i bijela trulež [Sclerotinia sclerotiorum (Lib.) de Bary, Sclerotinia minor Jagger] (Ivić, 2016), siva plijesan (Botrytis cinerea Pers.) (Miličević, 2016b), truleži korijena (Phytophthora nicotianae Breda de Haan, Phytophthora cryptogea Pethybr. \& Laff.) (Cvjetković i Sever, 2016), gljivična venuća [Verticillium albo-atrum Reinke \& Berthold, Verticillium dahliae Kleb., Fusarium oxysporum f. sp. lycopersici (Sacc.) W.C. Snyder \& H.N. Hansen] (Sever i Cvjetković, 2016). Na području Hrvatske dozvoljeno je ukupno 45 fungicidnih pripravaka, odnosno 29 djelatnih tvari iz 23 različitih kemijskih skupina (Tablica 1, Tablica 2) za suzbijanje bolesti rajčice na otvorenom. Najveći broj registriranih fungicida ima dozvolu za suzbijanje plamenjače rajčice (Tablica 1), koja je prema Cvjetkoviću (2016) i najučestalija bolest rajčice u Hrvatskoj.

Jedna od posljedica primjene fungicida je negativan popratni učinak na korisne mikroorganizme koji su prirodno prisutni u tlu ili koji se u tlo naknadno unose (Clapperton i sur., 2012). U najgorem slučaju, fungicidi mogu imati negativan popratni učinak na mikorizne vrste koje se inokuliraju na korijen rajčice (Clapperton i sur., 2012) s ciljem postizanja dodatnog prinosa i povećanja kvalitete postojeće proizvodnje. 
Tablica 1. Popis registriranih fungicida za suzbijanje bolesti rajčice u Republici Hrvatskoj u 2018. godini prema bazi FIS

Table 1 Fungicides authorized for tomato disease management in the Republic of Croatia during 2018 according to FIS database

\begin{tabular}{|c|c|c|c|}
\hline $\begin{array}{l}\text { Trgovački naziv / } \\
\text { Trade name }\end{array}$ & Djelatna tvar / Active ingredient & $\begin{array}{c}\text { Pokretljivost } \\
\text { fungicida / } \\
\text { Fungicide mobility }\end{array}$ & $\begin{array}{c}\text { Uzročnik } \\
\text { bolesti } \\
\text { / Causal } \\
\text { agent }\end{array}$ \\
\hline \multicolumn{4}{|c|}{ Način primjene: prskanje/raspršivanje } \\
\hline Acrobat MZ WG & Mankozeb + Dimetomorf / Mancozeb + Dimethomorph & KS & PI \\
\hline Armetil M & Mankozeb + Metalaksil / Mancozeb + Methalaxyl & KS & $\mathrm{PI}$ \\
\hline $\begin{array}{l}\text { Bordoška Juha } 20 \\
\text { Wp-Manica }\end{array}$ & $\begin{array}{l}\text { Bakar (Bakar hidroksid - kalcij sulfat kompleks) / Copper } \\
\text { (Copper hydroxide - calcium sulfate complex) }\end{array}$ & K & $\mathrm{PI}, \mathrm{SL}$ \\
\hline Curzate B WG & $\begin{array}{c}\text { Cimoksanil + Bakarni oksiklorid / Cymoxanil + Copper } \\
\text { oxychloride }\end{array}$ & KS & $\mathrm{PI}$ \\
\hline Difcor & Difenkonazol / Difenoconazole & $S$ & $\begin{array}{l}\text { AS, CF, SL, } \\
\text { PU, LT }\end{array}$ \\
\hline Dithane DG Neotec & Mankozeb / Mancozeb & K & PI \\
\hline Dithane M-45 & Mankozeb / Mancozeb & K & $\mathrm{Pl}$, AS \\
\hline Electis WG & Zoksamid + Mankozeb / Zoxamide + Mancozeb & K & $\mathrm{Pl}, \mathrm{SL}$ \\
\hline Equation Pro & Famoksadon + Cimoksanil / Famoxadone + Cymoxanil & K & $\mathrm{PI}$ \\
\hline Fantic M & Mankozeb + Benalaksil M / Mancozeb + Benalaxyl-M & KS & $\mathrm{PI}$ \\
\hline Galben C & $\begin{array}{c}\text { Benalaksil + Bakarni oksiklorid / Benalaxyl + Copper } \\
\text { oxychloride }\end{array}$ & KS & $\mathrm{PI}$ \\
\hline Galben M & Benalaksil + Mankozeb / Benalaxyl + Mancozeb & KS & $\mathrm{PI}$ \\
\hline Indofil 80 WP & Mankozeb / Mancozeb & K & $\mathrm{PI}$ \\
\hline Mankozeb & Mankozeb / Mancozeb & K & $\mathrm{PI}$ \\
\hline Manfil 75 WG & Mankozeb / Mancozeb & K & $\mathrm{PI}$ \\
\hline Manfil 80 WP & Mankozeb / Mancozeb & K & PI \\
\hline $\begin{array}{l}\text { Microthiol Special } \\
\text { Disperss }\end{array}$ & Sumpor / Sulphur & K & LT, ON \\
\hline Neoram WG & Bakarni oksiklorid / Copper oxychloride & K & $\mathrm{PI}$ \\
\hline Ortiva & Azoksistrobin / Azoxystrobin & $S$ & $\begin{array}{l}\mathrm{PI}, \mathrm{AS}, \mathrm{CF}, \\
\mathrm{OL}\end{array}$ \\
\hline Ortiva Top & $\begin{array}{c}\text { Azoksistrobin + Difenkonazol / Azoxystrobin + } \\
\text { Difenoconazole }\end{array}$ & $S$ & PI, AS, LT \\
\hline Orvego & $\begin{array}{c}\text { Dimetomorf }+ \text { Ametokradin / Dimethomorph + } \\
\text { Ametoctradin }\end{array}$ & KS & PI \\
\hline Penncozeb 75 DG & Mankozeb / Mancozeb & K & $\mathrm{PI}$ \\
\hline Pergado MZ & $\begin{array}{c}\text { Mandipropamid + Mankozeb / Mandipropamid + } \\
\text { Mancozeb }\end{array}$ & KS & $\mathrm{PI}$ \\
\hline Pinozeb M-45 & Mankozeb / Mancozeb & $\mathrm{K}$ & $\mathrm{PI}, \mathrm{AS}$ \\
\hline
\end{tabular}




\begin{tabular}{|c|c|c|c|}
\hline $\begin{array}{l}\text { Trgovački naziv / } \\
\text { Trade name }\end{array}$ & Djelatna tvar / Active ingredient & $\begin{array}{c}\text { Pokretljivost } \\
\text { fungicida / } \\
\text { Fungicide mobility }\end{array}$ & $\begin{array}{c}\text { Uzročnik } \\
\text { bolesti } \\
\text { / Causal } \\
\text { agent }\end{array}$ \\
\hline \multicolumn{4}{|c|}{ Način primjene: prskanje/raspršivanje } \\
\hline Polyram DF & Metiram / Metiram & $\mathrm{K}$ & PI \\
\hline Proxanil $450 \mathrm{SC}$ & Cimoksanil + Propamokarb / Cymoxanil + Propamocarb & KS & PI \\
\hline Ranman 400 SC & Ciazofamid / Cyazofamid & $\mathrm{K}$ & PI \\
\hline Ranman TOP & Ciazofamid / Cyazofamid & K & $\mathrm{PI}$ \\
\hline Revus & Mandipropamid / Manipropamid & $\mathrm{S}$ & $\mathrm{PI}$ \\
\hline $\begin{array}{l}\text { Ridomil Gold Mz } \\
\text { Pepite }\end{array}$ & Metalaksil-M + Maknkozeb / Methalaxyl-M + Mancozeb & KS & $\mathrm{PI}$ \\
\hline Ridomil Gold R & $\begin{array}{c}\text { Metalaksil-M + Bakrov oksiklorid / Methalaxyl-M + } \\
\text { Copper oxychloride }\end{array}$ & KS & $\mathrm{PI}$ \\
\hline Scala & Pirimetanil / Pyrimethanil & $\mathrm{K}$ & $\mathrm{BC}$ \\
\hline $\begin{array}{l}\text { Sphinx Extra } 685 \\
\text { WDG }\end{array}$ & Folpet + Dimetomorf / Folpet + Dimethomorph & KS & $\mathrm{PI}$ \\
\hline Signum & Piraklostrobin + Boskalid / Pyraclostrobin + Boscalid & KS & $\mathrm{LT}, \mathrm{BC}$ \\
\hline Star 80 WP & Mankozeb / Mancozeb & $\mathrm{K}$ & $\mathrm{PI}$ \\
\hline Stroby WG & Krezoksim-metil / Kresoxim-methyl & $\mathrm{S}$ & LT \\
\hline Sulgran & Sumpor / Sulphur & K & LT, ON \\
\hline Switch 62,5 WG & Ciprodinil + Fludioksonil / Cypronidil + Fludioxonil & KS & $\mathrm{SC}, \mathrm{BC}$ \\
\hline Systhane $20 \mathrm{EW}$ & Miklobutanil / Myclobutanil & $\mathrm{S}$ & LT \\
\hline Teldor SC 500 & Fenheksamid / Fenhexamid & $\mathrm{K}$ & $\mathrm{SC}, \mathrm{BC}$ \\
\hline Vincare & Folpet + Bentiavalikarb / Folpet + Benthiavalicarb & KS & $\mathrm{PI}$ \\
\hline Zaftra Azt 250 SC & Azoksistrobin / Azoxystrobin & $\mathrm{S}$ & $\mathrm{PI}, \mathrm{CF}, \mathrm{OL}$ \\
\hline Zakeo 250 SC & Azoksistrobin / Azoxystrobin & $\mathrm{S}$ & $\mathrm{PI}, \mathrm{CF}, \mathrm{OL}$ \\
\hline \multicolumn{4}{|c|}{ Način primjene: prskanje/raspršivanje, primjena u tlo navodnjavanjem kap-po-kap } \\
\hline Previcur Energy & Fosetil-Al + Propamokarb / Fosetyl-Al + Propamocarb & KS & PY \\
\hline Proplant & Propamokarb / Propamocarb & $\mathrm{S}$ & $\mathrm{PY}, \mathrm{PH}, \mathrm{PI}$ \\
\hline
\end{tabular}

Pokretljivost fungicida / Fungicide mobility: KS - kontaktno + sistemično / contact + systemic, K - kontaktno / contact, S - sistemično / systemic; Uzročnici bolesti / Causal agents: $P$. infestans - PI, A. solani- AS, B. cinerea- BC, L. taurica (- LT, Oidium neolycopersici L. Kiss - ON, Oidium lycopersici Cooke \& Massee - OL, S. lycopersici - SL, Cladosporium fulvum Cooke - CF, Sclerotinia spp. Fuckel - SC, Pythium spp. Nees - PY, Phytophthora spp. De Bary - PH, Puccinia spp. P. Micheli - PU.

Izvor/Source: FIS baza podataka / FIS database 
Tablica 2. Popis i podjela dozvoljenih djelatnih tvari za suzbijanje bolesti rajčice u Republici Hrvatskoj u 2018. godini prema bazama FIS i FRAC

Table 2 Active ingredients authorized for tomato disease management in the Republic of Croatia during 2018 according to FIS and FRAC databases

\begin{tabular}{|c|c|c|c|}
\hline $\begin{array}{c}\text { Djelatna tvar / Active } \\
\text { ingredient }\end{array}$ & $\begin{array}{c}\text { FRAC mehanizam } \\
\text { djelovanja (m.d.) / FRAC } \\
\text { MoA groups }\end{array}$ & $\begin{array}{l}\text { Biokemijski način djelovanja / } \\
\text { FRAC target site }\end{array}$ & $\begin{array}{l}\text { Kemijska skupina / } \\
\text { Chemical group }\end{array}$ \\
\hline Benalaksil / Benalaxyl & \multirow{4}{*}{$\begin{array}{c}\text { A: Metabolizam nukleinske } \\
\text { kiseline / Nucleic acids } \\
\text { metabolism }\end{array}$} & \multirow{4}{*}{$\begin{array}{c}\text { A1: RNA polimeraza I / RNA } \\
\text { polymerase I }\end{array}$} & \multirow{4}{*}{ Acilalanini / Acylalanines } \\
\hline Metalaksil / Methalaxyl & & & \\
\hline $\begin{array}{l}\text { Metalaksil-M / } \\
\text { Methalaxyl-M }\end{array}$ & & & \\
\hline $\begin{array}{l}\text { Benalaksil-M / } \\
\text { Benalaxyl-M }\end{array}$ & & & \\
\hline Zoksamid / Zoxamide & $\begin{array}{l}\text { B: Citoskeleton i motorni } \\
\text { proteini / Cytoskeleton } \\
\text { and motor protein }\end{array}$ & $\begin{array}{l}\text { B3: Stvaranje ß-tubulina u mitozi } \\
\text { / ß-tubulin assembly in mitosis }\end{array}$ & Toluamidi / Toluamides \\
\hline Boksalid / Boscalid & \multirow{7}{*}{ C: Disanje / Respiration } & $\begin{array}{l}\text { C2: Kompleks II: sukcinat- } \\
\text { dehidrogenaza / Complex II: } \\
\text { succinate-dehydro-genase }\end{array}$ & $\begin{array}{l}\text { Piridin karboksamidi / } \\
\text { Pyridine- carboxamides }\end{array}$ \\
\hline $\begin{array}{l}\text { Krezoksim-metil/ } \\
\text { Kresoxim-methyl }\end{array}$ & & \multirow{4}{*}{$\begin{array}{l}\text { C3: Kompleks III: citokrom bc } / \\
\text { Complex III: cytochrome bc }\end{array}$} & $\begin{array}{l}\text { Oksimino acetati / } \\
\text { Oximino-acetates }\end{array}$ \\
\hline $\begin{array}{l}\text { Famoksadon / } \\
\text { Famoxadone }\end{array}$ & & & $\begin{array}{c}\text { Oksazolidini / } \\
\text { Oxazolidine-diones }\end{array}$ \\
\hline $\begin{array}{l}\text { Piraklostrobin / } \\
\text { Pyraclostrobin }\end{array}$ & & & $\begin{array}{l}\text { Metoksikarbamati / } \\
\text { Methoxy-carbamates }\end{array}$ \\
\hline $\begin{array}{l}\text { Azoksistrobin / } \\
\text { Azoxystrobin }\end{array}$ & & & $\begin{array}{l}\text { Metoksi-akrilati / } \\
\text { Methoxy-acrylates }\end{array}$ \\
\hline $\begin{array}{l}\text { Ciazofamid / } \\
\text { Cyazofamid }\end{array}$ & & $\begin{array}{l}\text { C4: Kompleks III: citokrom bc1 / } \\
\text { Complex III: cytochrome bc1 }\end{array}$ & $\begin{array}{l}\text { Cianoimidazoli / Cyano- } \\
\text { imidazole }\end{array}$ \\
\hline $\begin{array}{l}\text { Ametokradin / } \\
\text { Ametoctradin }\end{array}$ & & $\begin{array}{l}\text { C8: Kompleks III citokrom bc1 / } \\
\text { Complex III: } \\
\text { cytochrome bc1 }\end{array}$ & $\begin{array}{l}\text { Triazolo-pirimidilamini / } \\
\text { Triazolo-pyrimidylamine }\end{array}$ \\
\hline Ciprodinil / Cyprodinil & \multirow{2}{*}{$\begin{array}{l}\text { D: Sinteza aminokiselina i } \\
\text { bjelančevina / Amino acids } \\
\text { and protein synthesis }\end{array}$} & \multirow{2}{*}{$\begin{array}{l}\text { D1: Biosinteza metionina / } \\
\text { Methionine biosynthesis }\end{array}$} & \multirow{2}{*}{$\begin{array}{l}\text { Anilino pirimidini / } \\
\text { Anilino-pyrimidines }\end{array}$} \\
\hline $\begin{array}{l}\text { Pirimetanil / } \\
\text { Pyrimethanil }\end{array}$ & & & \\
\hline $\begin{array}{l}\text { Fludioksonil / } \\
\text { Fludioxinil }\end{array}$ & $\begin{array}{l}\text { E: Prijenos signalnih } \\
\text { molekula / Signal } \\
\text { transduction }\end{array}$ & $\begin{array}{c}\text { E2: MAP / histidin-kinaza u } \\
\text { osmotskom prijenosu signala / } \\
\text { MAP/Histidine- Kinase in osmotic } \\
\text { signal transduction }\end{array}$ & $\begin{array}{c}\text { Fenilpiroli / } \\
\text { Phenylpyrroles }\end{array}$ \\
\hline $\begin{array}{c}\text { Propamokarb / } \\
\text { Propamocarb }\end{array}$ & $\begin{array}{c}\text { F: Sinteza ili prijenos } \\
\text { lipida - cjelovitost ili } \\
\text { funkcionalnost membrane } \\
\text { / Lipid synthesis or } \\
\text { transport - membrane } \\
\text { integrity or function }\end{array}$ & $\begin{array}{c}\text { F4: Propusnost stanične } \\
\text { membrane, lipida / Cell } \\
\text { membrane permeability, fatty } \\
\text { acids }\end{array}$ & Karbamati / Carbamates \\
\hline
\end{tabular}




\begin{tabular}{|c|c|c|c|}
\hline $\begin{array}{c}\text { Djelatna tvar / Active } \\
\text { ingredient }\end{array}$ & $\begin{array}{c}\text { FRAC mehanizam } \\
\text { djelovanja (m.d.) / FRAC } \\
\text { MoA groups }\end{array}$ & $\begin{array}{l}\text { Biokemijski način djelovanja / } \\
\text { FRAC target site }\end{array}$ & $\begin{array}{l}\text { Kemijska skupina / } \\
\text { Chemical group }\end{array}$ \\
\hline $\begin{array}{l}\text { Difenkonazol / } \\
\text { Difenoconazole }\end{array}$ & \multirow{3}{*}{$\begin{array}{c}\text { G: Biosinteza sterola } \\
\text { u membranama / } \\
\text { Sterol biosynthesis in } \\
\text { membranes }\end{array}$} & $\begin{array}{c}\text { G1: C14-demetilaza u biosintezi } \\
\text { sterola / }\end{array}$ & \multirow{2}{*}{ Triazoli / Triazoles } \\
\hline $\begin{array}{l}\text { Miklobutanil/ } \\
\text { Myclobutanil }\end{array}$ & & $\begin{array}{l}\text { C14-demethylase in sterol } \\
\text { biosynthesis }\end{array}$ & \\
\hline $\begin{array}{l}\text { Fenheksamid / } \\
\text { Fenhexamid }\end{array}$ & & $\begin{array}{l}\text { G3: 3-keto reduktaza, C4- } \\
\text { demitilacija / } \\
\text { 3-keto reductase, C4- de- } \\
\text { methylation }\end{array}$ & $\begin{array}{l}\text { Hidroksianilidi / } \\
\text { Hydroxyanilides }\end{array}$ \\
\hline $\begin{array}{l}\text { Dimetomorf / } \\
\text { Dimethomorph }\end{array}$ & \multirow{3}{*}{$\begin{array}{l}\text { H: Biosinteza stanične } \\
\text { stijenke / Cell wall } \\
\text { biosynthesis }\end{array}$} & \multirow{3}{*}{$\begin{array}{l}\text { H5: Sinteza celuloze / Cellulose } \\
\text { synthase }\end{array}$} & $\begin{array}{c}\text { Amidi karboksilnih } \\
\text { kiselina / Carboxylic Acid } \\
\text { Amides }\end{array}$ \\
\hline $\begin{array}{l}\text { Mandipropamid / } \\
\text { Mandipropamid }\end{array}$ & & & $\begin{array}{c}\text { Amidi mandelične } \\
\text { kiseline / Mandelic acid } \\
\text { amides }\end{array}$ \\
\hline $\begin{array}{l}\text { Bentiavalkarb / } \\
\text { Benthiavalicarb }\end{array}$ & & & $\begin{array}{l}\text { Vanilamid-karbamati / } \\
\text { Valinamide carbamates }\end{array}$ \\
\hline Mankozeb / Mancozeb & \multirow{5}{*}{$\begin{array}{l}\text { M: Tvari s višestrukim } \\
\text { mjestom aktivnosti / } \\
\text { Chemicals with multi-site } \\
\text { activity }\end{array}$} & \multirow{5}{*}{$\begin{array}{c}\text { M03: Višestruka kontaktna } \\
\text { aktivnost / Multi-site contact } \\
\text { activity }\end{array}$} & $\begin{array}{c}\text { Ditiokarbamati i srodnici } \\
\text { / Dithiocarbamates and } \\
\text { relatives }\end{array}$ \\
\hline Folpet / Folpet & & & Ftalimidi / phthalimides \\
\hline Bakar / Copper & & & \multirow{3}{*}{ Anorganski / Inorganic } \\
\hline & & & \\
\hline Sumpor / Sulphur & & & \\
\hline Fosetil-Al / Fosetyl-Al & $\begin{array}{l}\text { P: Induciranje otpornosti } \\
\text { biljke domaćina / Host } \\
\text { plant defence induction }\end{array}$ & P7: Fosfonati / Phosphonates & $\begin{array}{l}\text { Etil fosfonati / Ethyl } \\
\text { phosphonates }\end{array}$ \\
\hline Cimoksanil / Cymoxanil & $\begin{array}{l}\text { U: Nepoznat način } \\
\text { djelovanja / Unknown } \\
\text { mode of action }\end{array}$ & Nepoznat / Unknown & $\begin{array}{l}\text { Cianoacetamid-oksimi / } \\
\text { Cyanoacetamide-oxime }\end{array}$ \\
\hline
\end{tabular}

Izvor/Source: FIS baza podataka / FIS database; FRAC baza podataka (2018) / FRAC database (2018)

\section{Kompatibilnost fungicida i AMG}

Kolonizacija korijena AMG, prirodno zastupljenima u tlu ili inokuliranima primjenom komercijalnih pripravaka, može biti pod utjecajem različitih čimbenika od kojih, u proizvodnji rajčice na otvorenom, fungicidi mogu imati značajnu ulogu (Tablica 3). Mikorizne gljive mogu biti vrlo osjetljive na pojedine fungicide, no primjena pojedinih skupina fungicida i/ili djelatnih tvari (d.t.) može osigurati dovoljnu zaštitu od biljnih bolesti i nesmetani razvoj pojedinih AMG (Saia, 2011) (Tablica 3). Osim primjene pojedinih d.t. na razvoj AMG mogu utjecati i metoda primjene fungicida (Plenchette i sur., 2004; Plant Health Care Inc., 2009; Hernández-Dorrego i Mestre Parés, 2010), učestalost primjene i koncentracija primijenjene d.t. (Schreiner i Bethlenfalvay, 1997), način pokretljivosti fungicida u biljci (Plant Health Care Inc., 2009; HernándezDorrego i Mestre Parés, 2010), osjetljivost vrste ili soja AMG (Fontanet i sur., 1998; Kjøller i Ro- 
sendahl, 2000), period primjene fungicida u odnosu na životni ciklus AMG (sporulacija, rast micelija, kolonizacija) (Giovannetti i sur., 2006) (Tablica 3). Zabilježeni su i izuzeci kada pojedini fungicidi, poput d.t. fosetil-Al, pozitivno utječu na razvoj AMG, ali su rezultati u dostupnoj literaturi za navedenu d.t. kontradiktorni (Sucarno i sur., 1998; Rutto i sur., 1999; Giovanetti i sur., 2006). Ekološka proizvodnja ne osigurava u potpunosti nesmetanu kolonizaciju, postojećih ili primijenjenih komercijalnih pripravaka s AMG, ali je vjerojatnost postizanja boljih rezultata kolonizacije korijena i simbioze zasigurno veća (Saia, 2011).

Korelacija između metode primjene fungicida i razvoja mikoriznih vrsta:

1. Tretiranje sjemena može biti štetnije za razvoj mikoriza u odnosu na primjenu fungicida nakon kolonizacije korijena biljke domaćina (Plenchette i Perrin, 1992);

2. Folijarna primjena kontaktnih fungicida ima smanjen negativan popratni učinak na mikorizne vrste, s obzirom na reduciranu koncentraciju d.t. koja dospijeva u zonu korijena kultivirane biljne vrste pa se može nesmetano provoditi (Plant Health Care Inc., 2009). Pojedini sistemični fungicidi nemaju negativan utjecaj na razvoj AMG kada su primijenjeni nakon nastupanja kolonizacije (Tablica 3) (Hernández-Dorrego i Mestre Parés, 2010). U Hrvatskoj ukupno 19 kontaktnih fungicida ima dozvolu za primjenu na rajčici na otvorenom i kao takvi čine potencijal za kompatibilnost u proizvodnji rajčice čiji je korijen inokuliran AMG;

3. lako primjena kontaktnih fungicida u tlo, navodnjavanjem i/ili zalijevanjem, nije česta u proizvodnim uvjetima, može u potpunosti spriječiti razvoj AMG, posebice ukoliko primjena fungicida prethodi kolonizaciji korijena. Deponiranje d.t. u zonu korijena može u potpunosti uništiti micelij mikoriznih vrsta, ukoliko prethodno nije razvijen u tkivu korijena biljke domaćina, ali nakon smanjenja koncentracije primijenjene d.t. mikorizne vrste mogu ponovo iz tkiva korijena kolonizirati tlo (Plant Health Care Inc., 2009);

4. Potapanje presadnica u otopinu fungicida može onemogućiti inokulaciju AMG;

5. Primjena sistemičnih fungicida može pričinjavati značajne štete i onemogućiti inokulaciju mikoriznih vrsta, ali inhibitorni učinak smanjuje se nakon postupnog pada koncentracije d.t. u tkivu korijena biljke domaćina (Plant Health Care Inc., 2009).

6. Kompatibilnost s fungicidima ovisi o d.t., mikoriznoj vrsti i biljci domaćinu, stoga se mogućnost primjene fungicida može značajno razlikovati ovisno o kulturi u kojoj se AMG primjenjuju (Hernández-Dorrego i Mestre Parés, 2010).

7. Fungicidi mogu imati različit popratni, pozitivan ili negativan, učinak ovisno o periodu primjene u odnosu na razvojni stadij AMG. Giovannetti i sur. (2006) su utvrdili da negativan popratni učinak primjene pojedinih d.t. (u laboratorijskim uvjetima) može biti različit ukoliko se njihova primjena provede prilikom klijanja spora ili rasta micelija AMG. Na klijanje spora negativno utječu bakrov hidroksid i mankozeb koji u potpunosti inhibiraju njihovo klijanje i u minimalnim dozama, dok d.t. fosetil-Al ne utječe na klijanje spora, ali djelomično umanjuje rast micelija (Giovannetti i sur., 2006).

8. Značajan negativan utjecaj na razvoj AMG mogu imati fungicidi s folijarnom primjenom, ukoliko dospiju u tlo, pa je potreban dodatan oprez tijekom primjene fungicida prskanjem/raspršivanjem kako bi se izbjeglo zanošenje d.t. na tlo (Plenchette i Perrin, 1992; Hernández-Dorrego i Mestre Parés, 2010) (Tablica 3). Hernández-Dorrego i Mestre Parés (2010) utvrdili su na testiranim folijarnim fungicidima, neovisno o kemijskoj skupini i mehanizmu djelovanja, da značajno ometaju razvoj mikoriznih vrsta ukoliko dospiju u tlo. 
Tablica 3. Dostupni podaci o kompatibilnosti AMG i fungicida dozvoljenih za suzbijanje bolesti rajčice

Table 3 Available data on compatibility of AMF and fungicides authorized for tomato disease management

\begin{tabular}{|c|c|c|}
\hline Djelatna tvar / Active ingredient & $\begin{array}{l}\text { Kompatibilnost / } \\
\text { Compatibility }\end{array}$ & Primjena / Application \\
\hline Azoksistrobin / Azoxystrobin & $\mathrm{N}^{8(\mathrm{a})}, \mathrm{N} / \mathrm{O}^{8(\mathrm{~b})}$ & $T^{8(a)}, F^{8(b)}$ \\
\hline Bakar / Copper & $\mathrm{N}^{5,2,8(\mathrm{a})}, \mathrm{O}^{8(\mathrm{~b})}, \mathrm{N}^{2}, \mathrm{O}^{1}$ & $T^{8(a)}, F^{8(b)}$ \\
\hline Ciprodinil / Cyprodinil, Metiram / Metiram & $\mathrm{N}^{\mathrm{B}(\mathrm{a})}, \mathrm{O}^{\mathrm{B}(\mathrm{b})}$ & $T^{g(a)}, F^{8(b)}$ \\
\hline Difenkonazol / Difenoconazole & $\mathrm{N}^{4}$ & $\mathrm{~F}^{4}$ \\
\hline Dimetomorf / Dimethomorph & $\mathrm{O}^{8}$ & $F^{8}$ \\
\hline Fenheksamid / Fenhexamid & $\mathrm{N}^{8(a)}, \mathrm{O}^{8(b)}$ & $T^{8(a)}, F^{8(b)}$ \\
\hline Fludioksonil / Fludioxinil & $\mathrm{O}^{8}$ & $\mathrm{~F}^{8}$ \\
\hline Folpet / Folpet & $\mathrm{N}^{8(a)}, \mathrm{O}^{8(b)}$ & $T^{8(a)}, F^{8(b)}$ \\
\hline Fosetil-Al / Fosetyl-Al & $N^{5}, P^{8(a)}, O^{8(b)}$ & $I^{8(a)}, F^{8(b)}$ \\
\hline Krezoksim-metil / Kresoxim-methyl & $\mathrm{N}^{8(a)}, N / \mathrm{O}^{8(b)}$ & $T^{8(a)}, F^{8(b)}$ \\
\hline Mankozeb / Mancozeb & $\mathrm{O}^{5}, \mathrm{~N}^{8(\mathrm{a}), 6}, \mathrm{~N} / \mathrm{O}^{8(\mathrm{~b})}$ & $T^{8(a)}, F^{8(b), 6}$ \\
\hline Metalaksil / Methalaxyl & $\mathrm{N}^{8(a)}, \mathrm{N} / \mathrm{O}^{8(\mathrm{~b})}$ & $T^{8(a)}, F^{8(b)}$ \\
\hline Miklobutanil / Myclobutanil & $\mathrm{N}^{8}$ & $\mathrm{~T}^{8}$ \\
\hline Piraklostrobin / Pyraclostrobin & $\mathrm{N}^{6}$ & $\mathrm{~F}^{6}$ \\
\hline Propamokarb / Propamocarb & $\mathrm{O}^{8}, \mathrm{P}^{3}$, & $F^{8}, T^{8}, I^{3}$ \\
\hline Sumpor / Sulphur & $\mathrm{O}^{7}$ & $\mathrm{~F}^{7}$ \\
\hline
\end{tabular}

Kompatibilnost / Compatibility: $\mathrm{N}$ - negativan utjecaj / negative impact, $\mathrm{P}$ - pozitivan utjecaj / positive impact, O - izostanak utjecaja / no effect; Primjena / Application: F - folijarna primjena / foliar application, T - primjena putem tla / soil application, I - Primjena fungicida prije i nakon inokulacije mikoriznom vrstom / Fungicide application prior and after inoculation with mycorrhizal fungi.

Izvor / Source: Rhodes i Larser, 1981'1 / Rhodes and Larser, 1981'; Sreenivasa i Bagyaraj, $1989^{2}$ / Sreenivasa and Bagyaraj, 19892; Marin i sur., 2002³ / Marin et al., 2002 ${ }^{3}$; Nithya Meenakshil i sur., $2007^{4}$ / Nithya Meenakshil et al., 20074; Davies, $2008^{5}$ Campos i sur., 20096/ Campos et al., 20096; Plant Health Care Inc., 20097; Hernández-Dorrego i'Mestre Parés, 20108 / Hernández-Dorrego and Mestre Parés, $2010^{8}$

Uzmu li se u obzir kemijske skupine fungicida i njihov međuodnos s mikoriznim vrstama, u literaturi se navode sljedeće kompatibilnosti i/ili nekompatibilnosti:

Kemijske skupine koje najvjerojatnije nemaju negativan učinak na razvoj mikoriznih vrsta (Plant Health Care Inc., 2009; FRAC, 2018): (FRAC m.d. - A) acilalanini; (FRAC m.d. - B) benzimidazoli i tiofanati; (FRAC m.d. - D) ditiokarbamati; (FRAC m.d. - F) karbamati, fosforo-tiolati; (FRAC m.d. - G) hidroksianilidi, piperazini, pirimidini, piridini, morfolini; (FRAC m.d. - E) fenilpiroli, (FRAC m.d. - M) anorganski - sumpor, (FRAC m.d. - P) etil fosfonati;

Kemijske skupine koje najvjerojatnije imaju negativan učinak na razvoj mikoriznih vrsta (Plant Health Care Inc., 2009): (FRAC m.d. - C) imidazolinoni, (FRAC m.d. - F3) aromatski hidrokarbonati, tiadiazoli, (FRAC m.d. - M) anorganski - bakar, ftalimidi; 
Kemijske skupine koje imaju negativan, pozitivan ili neutralan učinak na razvoj mikoriznih vrsta (Plant Health Care Inc., 2009): (FRAC m.d. - E) dikarboksimidi; (FRAC m.d. - G) triazoli; (FRAC m.d. - I) karboksamidi; (FRAC m.d. - M) kloronitrili, sulfamidi.

U proizvodnim uvjetima na području Istarske županije redovito se primjenjuju fungicidi koji sadrže d.t. bakar i azoksistrobin. lako učinak fungicida na AMG nije bio glavni cilj naših istraživanja u sklopu VIP projekta „Optimizacija gnojidbe pri uzgoju industrijske rajčice primjenom mikoriznih gljiva", uzgoj rajčice za preradu s inokuliranim AMG pokazao je izostanak negativnog učinka bakra i azoksistrobina na postotak mikoriziranosti. Naime, u proizvodnim uvjetima primjena fungicida na bazi bakra i/ili azoksistrobina, nakon inokulacije AMG, nije negativno utjecala na postotak mikoriziranosti korijena koji je bio i do $88 \%$. Slična iskustva s primjenom bakrenih fungicida potvrđena su i od znanstvenika u Italiji (Colla, 2017, usmena komunikacija).

U proizvodnji rajčice na otvorenom potrebno je voditi računa, osim o kompatibilnosti primijenjenih fungicida i AMG, o potencijalnim ostacima pesticida u tlu u slučaju plodoreda. lako većinu pesticida mogu razgraditi mikroorganizmi prisutni u tlu, odnosno do razgradnje pesticida dovode određeni abiotski čimbenici, možemo pretpostaviti da njihovo nakupljanje u tlu može otežati ili onemogućiti mikorizaciju rajčice. U tom bi slučaju, unatoč izostanku primjene fungicida potencijalno štetnih za mikorizne vrste, mikorizacija nasada rajčice mogla u potpunosti izostati. Degradacija rezidua fungicida u tlu, koja je različita ovisno o primijenjenoj d.t., osigurava sigurnu primjenu mikoriznih vrsta.

\section{Zaključak}

Fungicidi su sredstva za zaštitu bilja koji se u poljoprivrednoj proizvodnji redovito koriste za suzbijanje uzročnika biljnih bolesti. Obzirom na spektar djelovanja, mogu imati inhibitoran učinak na AMG. Veliki je broj čimbenika koji utječu na kompatibilnost fungicida i AMG, a to su djelatna tvar, vrsta AMG, način inokulacije, biljka domaćin, (a)biotski uvjeti i drugo. Pregledom literature na temu kompatibilnosti AMG i fungicida i naših dosadašnjih istraživanja primjene mikoriznih gljiva u proizvodnim uvjetima pokazalo se da uz prilagođenu poljoprivrednu praksu pojedini fungicidi mogu biti kompatibilni s razvojem AMG. No, za utvrđivanje točnog utjecaja određenog fungicida u proizvodnim uvjetima, zastupljenih na području Hrvatske, potrebno je provesti dodatne pokuse kompatibilnosti.

\section{Napomena/Zahvala}

Ovaj rad je nastao u sklopu provođenja VIP projekta „Optimizacija gnojidbe pri uzgoju industrijske rajčice primjenom mikoriznih gljiva" kojeg financira Vijeće za istraživanja u poljoprivredi - Ministarstvo poljoprivrede (Ugovor br. 2016-14-45), a sufinancira Istarska županija.

\section{Literatura}

Al-Karaki, G.N. (2006) Nursery inoculation of tomato with arbuscular mycorrhizal fungi and subsequent performance under irrigation with saline water. Scientia Horticulturae, 109 (1), 1-7. DOI: https://doi.org/10.1016/j.scienta.2006.02.019

Augé, R.M. (2004) Arbuscular mycorrhizae and soil/plant water relations. Canadian Journal of Soil Science, 84 (4), $373-$ 381. DOl: https://doi.org/10.4141/S04-002

Baum, C., El-Tohamy, W., Gruda, N. (2015) Increasing the productivity and product quality of vegetable crops using arbuscular mycorrhizal fungi: a review. Scientia Horticulturae, 187, 131-141. DOI: https://doi.org/10.1016/j.scienta.2015.03.002

Berruti, A., Lumini, E., Balestrini, R., Bianciotto, V. (2015) Arbuscular mycorrhizal fungi as natural biofertilizers: let's benefit from past successes. Frontiers in Microbiology, 6, 1559. DOI: 10.3389/fmicb.2015.01559

Borošić, J. (2016) Uvjeti proizvodnje rajčice. Glasilo biljne zaštite, 16 (5), 423-427. URL: https://hrcak.srce.hr/169644 (18.9.2018.)

Bowles, T.M., Barrios-Masias, F.H., Carlisle, E.A., Cavagnaro, T.R., Jackson, L.E. (2016) Effects of arbuscular mycorrhizae on tomato yield, nutrient uptake, water relations, and soil carbon dynamics under deficit irrigation in field conditions. Science of the Total Environment, 566, 1223-1234. DOI: http://dx.doi.org/10.1016/j.scitotenv.2016.05.178

Campos, A.A.B., Scotton, J.C., Costa, W.L.F., Giassi, V., Pinto, D.F.P., Homma, S.K. (2015) Seleção de fungicidas visando à preservação de fungos micorrízicos arbusculares nativos no cultivo do feijoeiro. Revista Brasileira de Engenharia Agrícola e Ambiental, 19 (9), 898-902. DOI: http://dx.doi.org/10.1590/1807-1929/agriambi.v19n9p898-902 
Cavagnaro, T.R., Jackson, L.E., Six, J., Ferris, H., Goyal, S., Asami, D., Scow, K.M. (2006) Arbuscular mycorrhizas, microbial communities, nutrient availability, and soil aggregates in organic tomato production. Plant and Soil, 282 (1-2), $209-225$. DOI: https://doi.org/10.1007/s11104-005-5847-7

Clapperton, J., Regen, M. (2012) Pesticide effects on soil biology. No-till on the Plains, 8 (1), 4-7. URL: https://gardendrum.com/wp-content/uploads/2012/11/PesticideEffectsOnSoilBiology.pdf (20.9.2018.)

Conversa, G., Elia, A., La Rotonda, P. (2007) Mycorrhizal inoculation and phosphorus fertilization effect on growth and yield of processing tomato. Acta Horticulturae, 758, 333-338. DOI: 10.17660/ActaHortic.2007.758.43

Conversa, G., Lazzizera, C., Bonasia, A., Elia, A. (2013) Yield and phosphorus uptake of a processing tomato crop grown at different phosphorus levels in a calcareous soil as affected by mycorrhizal inoculation under field conditions. Biology and Fertility of Soils, 49 (6), 691-703. DOI: https://doi.org/10.1007/s00374-012-0757-3

Copetta, A., Bardi, L., Bertolone, E., Berta, G. (2011) Fruit production and quality of tomato plants (Solanum lycopersicum L.) are affected by green compost and arbuscular mycorrhizal fungi. Plant Biosystems, 145 (1), 106-115. DOl: https:// doi.org/10.1080/11263504.2010.539781

Cvjetković, B. (2016) Plamenjača rajčice [Phytophthora infestans (Mont.) de Bary]. Glasilo biljne zaštite, 16 (5), $477-481$. URL: https://hrcak.srce.hr/169652 (18.9.2018.)

Cvjetković, B., Sever, Z. (2016) Trulež korijena rajčice (Phytophthora nicotianae Breda de Haan). Glasilo biljne zaštite, 16 (5), 509-511. URL: https://hrcak.srce.hr/169659 (18.9.2018.)

Davies, F.T. (2008) Opportunities from down under: How mycorrhizal fungi can benefit nursery propagation and production systems. U: Combined Proceedings International Plant Propagators' Society, 58, 539-548. URL: https://pdfs.semanticscholar.org/df5c/1303fa93330fd7882d786cfee2ee75114ce1.pdf (15.9.2018.)

Douds Jr, D.D., Lee, J., Rogers, L., Lohman, M.E., Pinzon, N., Ganser, S. (2012) Utilization of inoculum of AM fungi produced on-farm for the production of Capsicum annuum: a summary of seven years of field trials on a conventional vegetable farm. Biological Agriculture \& Horticulture, 28 (2), 129-145. DOl: https://doi.org/10.1080/01448765.2012.693362

FIS baza. Fitosanitarni informacijski sustav. URL: https://fis.mps.hr/TrazilicaSZB/Default.aspx?lan=hr-Hr (16.09.2018.)

Fontanet, X., Estaún, V., Camprubi, A., Calvet, C. (1998) Fungicides added to potting substrate affect mycorrhizal symbiosis between a peach-almond rootstock and Glomus sp. HortScience, 33 (7), 1217-1219. URL: http://hortsci.ashspublications.org/content/33/7/1217.short (15.9.2018.)

FRAC (2018) Fungicide resistance action committee. URL: http://www.frac.info/publications/downloads (14.9.2018.)

Giovannetti, M., Avio, L. (2002) Biotechnology of arbuscular mycorrhizas. U: G.G. Khachatourians, D.K. Arora, ur. Applied mycology and biotechnology: Volume 2, Agriculture and food production. Netherlands: Elsevier.

Giovannetti, M., Turrini, A., Strani, P., Sbrana, C., Avio, L., Pietrangeli, B. (2006) Mycorrhizal fungi in ecotoxicological studies: soil impact of fungicides, insecticides and herbicides. Prevention Today, 2 (1-2), 47-62. URL: https://www.beyondpesticides.org/assets/media/documents/Mycorrhizal_fungi_in_ecotoxicological_studies_Soil.pdf (14.9.2018.)

Hernández-Dorrego, A., Mestre Parés, J. (2010) Evaluation of some fungicides on mycorrhizal symbiosis between two Glomus species from commercial inocula and Allium porrum L. seedlings. Spanish Journal of Agricultural Research, 8 (S1), S43-S50. DOI: 10.5424/sjar/201008S1-1222

Ivić, D. (2016) Bijela trulež (Sclerotinia sclerotiorum (Lib.) de Bary) na rajčici. Glasilo biljne zaštite, 16 (5), 500-504. URL: https://hrcak.srce.hr/169657 (18.9.2018.)

Kjøller, R., Rosendahl, S. (2000) Effects of fungicides on arbuscular mycorrhizal fungi: differential responses in alkaline phosphatase activity of external and internal hyphae. Biology and Fertility of Soils, 31 (5), 361-365. DOI: https://doi. org/10.1007/s003749900180

Latef, A.A.H.A., Chaoxing, H. (2011) Effect of arbuscular mycorrhizal fungi on growth, mineral nutrition, antioxidant enzymes activity and fruit yield of tomato grown under salinity stress. Scientia Horticulturae, 127 (3), 228-233. DOI: https:// doi.org/10.1016/j.scienta.2010.09.020

Maceljski, M., Cvjetković, B., Ostojić, Z., Igrc-Barčić, J., Pagliarini, N., Oštrec, Lj., Barić,. K., Čizmić, I. (2004) Štetočine povrća. Čakovec: Zrinski d.d..

Marin, M., Ybarra, M., Fé, A., García-Férriz, L. (2002) Effect of arbuscular mycorrhizal fungi and pesticides on Cynara cardunculus growth. Agricultural and Food Science in Finland, 11 (3), 245-251. URL: http://jukuri.luke.fi/handle/10024/453210 (15.9.2018.)

Marschner, P. (2012) Rhizosphere biology. U: P. Marschner, ur. Marschner's Mineral Nutrition of Higher Plants, Third edition. Academic Press.

Miličević, T. (2016a) Pepelnica rajčice [Leveillula taurica (Lev.) G. Arnaud; Pseudoidium neolycopersici (L. Kiss) L. Kiss]. Glasilo biljne zaštite, 16 (5), 489-492. URL: https://hrcak.srce.hr/169654 (18.9.2018.)

Miličević, T. (2016b) Siva plijesan rajčice (Botrytis cinerea Pers.). Glasilo biljne zaštite, 16 (5), 497-499. URL: https://hrcak. srce.hr/169656 (18.9.2018.)

Nithya Meenakshil, S., Manian, S., Jeyaramraja, P.R. (2007) Influence of Azoxystrobin and Difenconazole on N2-Fixing and Antagonistic Organisms. Pest Technology, 1 (2), 139-144. URL: http://www.academia.edu/download/45093624/ PT_12139-1440.pdf (17.9.2018.)

Oehl, F., Sieverding, E., Palenzuela, J., Ineichen, K. (2011) Advances in Glomeromycota taxonomy and classification. IMA Fungus, 2 (2), 191-199. DOI: https://doi.org/10.5598/imafungus.2011.02.02.10

Ortas, I., Sari, N., Akpinar, C., Yetisir, H. (2013) Selection of arbuscular mycorrhizal fungi species for tomato seedling growth, mycorrhizal dependency and nutrient uptake. European Journal of Horticultural Science, 78 (5), 209-218. URL: http://www.pubhort.org/ejhs/2013/file_4044268.pdf (12.9.2018.)

Plant ealth Care Inc. (2009) Effects of fungicides on mycorrhizal fungi and root colonization. URL: (16.9.2018.)

Plenchette, C., Perrin. R. (1992) Evaluation in the greenhouse of the effects of fungicides on the development of mycorrhiza on leek and wheat. Mycorrhiza, 1 (2), 59-62. DOI: https://doi.org/10.1007/BF00206137

Podravka (2018) URL: https://www.podravka.hr/kompanija/mediji/priopcenja/odlicni-rezultati-podravkine-pokusne-proizvodnje-rajcice-u-podravini/ (26.9.2018.)

Porcel, R., Aroca, R., Ruiz-Lozano, J.M. (2012) Salinity stress alleviation using arbuscular mycorrhizal fungi. A review. Agronomy for Sustainable Development, 32 (1), 181-200. DOI: https://doi.org/10.1007/s13593-011-0029-x

Poulton, J.L., Bryla, D., Koide, R.T., Stephenson, A.G. (2002) Mycorrhizal infection and high soil phosphorus improve vegetative growth and the female and male functions in tomato. New Phytologist, 154 (1), 255-264. DOI: https://doi. org/10.1046/j.1469-8137.2002.00366.x

Rhodes, L.H., Laser, P.O. (1981) Effects of fungicides on mycorrhizal development of creeping bentgrass (Agrostis palustris). Plant Disease, 65 (2), 145-147. URL: http://agris.fao.org/agris-search/search.do?recordID=US19820756318 
(13.9.2018.)

Rouphael, Y., Franken, P., Schneider, C., Schwarz, D., Giovannetti, M., Agnolucci, M., DePascale, S., Bonini, P., Colla, G. (2015) Arbuscular mycorrhizal fungi act as biostimulants in horticultural crops. Scientia Horticulturae, 196, 91-108. DOI: https://doi.org/10.1016/j.scienta.2015.09.002

Rutto, K.L., Ishii, T., Wamocho, S.L., Murakami, M. (1999) The effect of polyaminesand propamocrab on the growth and yield of tomato (Lycopersicon esculentum Mill.) plants grown in a low P tropical soil inoculated with a vesicular-arbuscular mycorrhizal fungus. Bulletin of the Faculty of Education Ehime University, Nat. Sci., 19 (2), 33-37. URL: https://core.ac.uk/ download/pdf/71501501.pdf (17.9.2018.)

Saia, S. (2011) Focus micorrize: una preziosa simbiosi. Agrisicilia, 9, 30-33.

Schalamuk, S., Velazquez, S., Simón, M.R., Cabello, M. (2014) Effect of septoria leaf blotch and its control with commercial fungicides, on arbuscular-mycorrhizal-fungal colonization, spore numbers, and morphotype diversity. Journal of Plant Protection Research, 54 (1), 9-14. DOI: https://doi.org/10.2478/jppr-2014-0002

Schreiner, R.P., Bethlenfalvay, G.J. (1995) Mycorrhizal interactions in sustainable agriculture. Critical Reviews in Biotechnology, 15 (3-4), 271-285. DOl: https://doi.org/10.3109/07388559509147413

Sever, Z., Cvjetković, B. (2016) Venuća rajčice uzrokovana patogenim gljivama iz rodova Verticillium i Fusarium. Glasilo biljne zaštite, 16 (5), 505-508. URL: https://hrcak.srce.hr/169658 (18.9.2018.)

Smith, S.E., Read, D.J. (2008) Mycorrhizal Symbiosis, Third edition. London: Academic Press.

Sreenivasa, M.N., Bagyaraj, D.J. (1989) Use of pesticides for mass production of vesicular-arbuscular mycorrhizal inoculum. Plant and Soil, 119 (1), 127-132. DOI: https://doi.org/10.1007/BF02370276

Statistički ljetopis Republike Hrvatske (2017), 262. URL: https://www.dzs.hr/Hrv/publication/stat_year.htm (11.9.2018.)

Sukarno, N., Smith, F.A., Scott, E.S., Jones, G.P., Smith, S.E. (1998) The effect of fungicides on vesicular-arbuscular mycorrhizal symbiosis. III. The influence of VA mycorrhiza on phytotoxic effects following application of fosetyl-Al and phosphonate. New Phytologist, 139 (2), 321-330. DOI: https://doi.org/10.1046/j.1469-8137.1998.00204.x

Sukarno, N., Smith, S.E., Scott, E.S. (1993) The effect of fungicides on vesicular-arbuscular mycorrhizal symbiosis. I. The effects on vesicular - arbuscular mycorrhizal fungi and plant growth. New Phytologist, 125 (1), 139-147. DOI: https://doi. org/10.1111/j.1469-8137.1993.tb03872.x

Šubić, M. (2016) Koncentrična pjegavost (Alternaria solani Sorauer) i septorijska pjegavost (Septoria lycopersici Speg.) rajčice. Glasilo biljne zaštite, 16 (5), 482-488. URL: https://hrcak.srce.hr/169653 (18.9.2018.)

Trappe, J.M., Molina, R., Castellano, M. (1984) Reactions od mycorrhizal fungi and mycorrhiza formation to pesticides. Annual Review of Phytopathology, 22, 331-359. DOl: https://doi.org/10.1146/annurev.py.22.090184.001555

Watts-Williams, S.J., Cavagnaro, T.R. (2012) Arbuscular mycorrhizas modify tomato responses to soil zinc and phosphorus addition. Biology and Fertility of Soils, 48 (3), 285-294. DOI: https://doi.org/10.1007/s00374-011-0621-x

Yadav, A., Aggarwal, A. (2014) Effect of Benomyl and Dithane M-45 on mycoflora, mycorrhizae and growth enhancement of Helianthus annuus L. New York Science Journal, 7 (11), 7-15. URL: http://www.sciencepub.net/newyork/ ny0711/002_27311ny071114_7_15.pdf (11.9.2018.)

Zocco, D., Fontaine, J., Lozanova, E., Renard, L., Bivort, C., Durand, R., Grandmougin-Ferjani, A., Declerck, S. (2008) Effects of two sterol biosynthesis inhibitor fungicides (fenpropimorph and fenhexamid) on the development of an ar-
buscular mycorrhizal fungus. Mycological Research, 112 (5), 592-601. DOl: https://doi.org/10.1016/j.mycres.2007.11.010

Zrnić, M., Širić, I. (2017) The application of mycorrhiza in horticulture. Journal of Central European Agriculture, 18 (3), 706-732. DOI: https://doi.org/10.5513/jcea.v18i3.5623

Prispjelo/Received: 28.9.2018

Prihvaćeno/Accepted: 15.10.2018.

Scientific review paper

\title{
Compatibility of fungicides and arbuscular mycorrhiza fungi in the open-field tomato production
}

\begin{abstract}
Arbuscular mycorrhizal fungi (AMF) are beneficial soil microorganisms that persist on roots of a significant number of plant species through symbiosis, including most of the economically important agricultural crops, where tomato takes a significant place for the Croatian area. Tomato has a high natural ability to interact with AMF, the benefits of which are significantly related to improved plant condition and resistance to different biotic and abiotic factors. Implementation of AMF is limited by production conditions, such as by application of fungicides that is regularly conduced in tomato production for fungal disease management. Although in tomato production mainly foliar fungicides are applied, significant quantity of applied active ingredient may indirectly reach the upper soil layer and negatively affect AMF development. The aim of this paper was to, based on available literature and research findings, describe the compatibility of AMF with fungicides allowed for application in open-field tomato production.

Keywords: arbuscular mycorrhizal fungi, mycorrhiza, Solanum lycopersicum L., fungicide, compatibility
\end{abstract}

